OPEN ACCESS

Edited by:

Daniel Behme,

Universitätsmedizin Göttingen,

Germany

Reviewed by:

Benjamin Friedrich,

Technische Universität München,

Germany

Kai Kallenberg,

Asklepios Kliniken Schildautal,

Germany

${ }^{*}$ Correspondence:

Philipp Bücke

philipp.buecke@gmail.com

Specialty section: This article was submitted to

Stroke,

a section of the journal

Frontiers in Neurology

Received: 25 August 2018 Accepted: 17 October 2018

Published: 20 November 2018

Citation:

Bücke P, Aguilar Pérez M, AIMatter M, Hellstern V, Bäzner $H$ and Henkes $H$

(2018) Functional Outcome and

Safety of Intracranial Thrombectomy After Emergent Extracranial Stenting in Acute Ischemic Stroke Due to Tandem Occlusions. Front. Neurol. 9:940. doi: 10.3389/fneur.2018.00940

\section{Functional Outcome and Safety of Intracranial Thrombectomy After Emergent Extracranial Stenting in Acute Ischemic Stroke Due to Tandem Occlusions}

\author{
Philipp Bücke ${ }^{1 *}$, Marta Aguilar Pérez ${ }^{2}$, Muhammad AlMatter ${ }^{2}$, Victoria Hellstern ${ }^{2}$, \\ Hansjörg Bäzner ${ }^{1}$ and Hans Henkes ${ }^{2}$ \\ ${ }^{1}$ Neurologische Klinik, Klinikum Stuttgart, Stuttgart, Germany, ${ }^{2}$ Klinik für Neuroradiologie, Klinikum Stuttgart, Stuttgart, \\ Germany
}

Background and Purpose: Various endovascular approaches to treat acute ischemic stroke caused by extra- intracranial tandem occlusions (TO) exist: percutaneous transluminal angioplasty with or without emergent extracranial carotid stenting (ECS) due to high-grade stenosis preceded or followed by intracranial mechanical and/or aspiration thrombectomy (MT). Which treatment strategy to use is still a matter of debate.

Methods: From our ongoing prospective stroke registry we retrospectively analyzed 1,071 patients with anterior circulation stroke getting endovascular treatment within $6 \mathrm{~h}$ of symptom onset. ECS prior to intracranial MT for TO $(n=222)$ was compared to MT as standard of care (control group; acute intracranial vessel occlusion without concomitant ipsilateral ICA-occlusion or high-grade stenosis [C; $n=849]$ ). Good functional outcome (mRS $\leq 2$ at 3 months), mortality rates, frequencies of symptomatic intracranial hemorrhage $(\mathrm{s} \mathrm{CH})$ and successful recanalization (Thrombolysis in Cerebral Infarction Score $[\mathrm{TICl}] 2 \mathrm{~b}$ or 3 ) were assessed. In subgroup analyses we tried to detect possible influences of stroke etiology, dual inhibition of platelet aggregation (IPA; clopidogrel [CLO]: $n=83$; ticagrelor [TIC]: $n=137$; in combination with Aspirin) and intravenous thrombolysis (IVT).

Results: Functional outcome was superior in TO (mRS 0-2: 44.6\%) when compared with controls (36.0\%; OR [95\% Cl]: 3.49 [1.59-7.67]; $p=0.002)$. There was no difference in all-cause mortality at 3 months (TO: $21.6 \%$; C: $27.7 \%$; 0.78 [0.47-1.29]; $p=$ 0.324), in-hospital mortality (0.76 [0.45-1.30]; $p=0.324)$, sICH (TO: 3.2\%; C: 5.0\%; 0.70 [0.30-1.59]; $p=0.389$ ), and $\mathrm{TICl} 2 \mathrm{~b} / 3$ (TO: 89.1\%; C: 88.3\%; $p=0.813$ ). In subgroupanalysis, TIC and CLO did not differ in functional outcome (TIC: 45.3\%; CLO: 44.6\%; 1.04 [0.51-2.09]; $p=0.920$ ) and mortality rates (all-cause mortality: TIC: $23.4 \%$; CLO: $16.9 \% ; 0.75$ [0.27-2.13]; $p=0.594)$. sICH was more frequent in $\mathrm{TIC}(n=7$ [5.1\%]) vs. CLO $(n=0 ; p=0.048)$.

Conclusion: In our pre-selected cohort, ECS prior to intracranial MT in TO allowed for a good functional outcome that was superior compared to a control population. Mortality 
rates did not differ. Despite a dual IPA in TO, there was no increase in SICH. CLO and TIC for dual IPA did not differ in terms out outcome and mortality rates. A significant increase in sICH was observed after initial loading with TIC.

Keywords: tandem occlusions, acute ischaemic stroke (AIS), endovascular therapy, thrombectomy, extracranial stenosis, functional outcome, inhibition of platelet aggregation

\section{INTRODUCTION}

Mechanical thrombectomy and/or aspiration thrombectomy (MT) in acute ischemic stroke due to embolic large vessel occlusion is effective and safe (1-5). Specific recommendations and national guidelines for indication, implementation, and patient selection exist (6). A considerable number of patients present with extracranial-intracranial tandem occlusions (TO; occlusion or high-grade stenosis of an extracranial internal carotid artery [ICA] with a concomitant ipsilateral intracranial large vessel occlusion) (7). Currently, there is a lack of guidance on how to treat those patients. Several endovascular treatment strategies are proposed: percutaneous transluminal angioplasty (PTA) with or without emergent stenting of the extracranial ICA (ECS) preceded or followed by MT (7-10). Which technique to use is still a matter of debate (11-14). We report data on TO where initial ECS is followed by MT (extracranial first).

\section{MATERIALS AND METHODS}

\section{Study Population}

Consecutive patients from our prospective single-center stroke registry treated with MT between January 2010 and December 2017 were screened and retrospectively analyzed. Patients with an anterior circulation ischemic stroke caused by an occlusion of the ICA, the carotid-T, an M1- or M2-branch of the middle cerebral artery (MCA) were included. We did not consider distal MCAocclusions, occlusions of the anterior cerebral artery or posterior circulation stroke. Proximal vessel occlusions (on initial imaging) that were found recanalized during angiography (spontaneously or as an effect of intravenous thrombolysis [IVT]) were removed from further analysis. Patients treated after $6 \mathrm{~h}$ of symptom onset or presenting with wake-up stroke or unknown symptom onset were excluded. We did not include cases of primary stentangioplasty without MT (due to high-grade intra- or extracranial stenosis or dissection). Datasets without a 3-month follow-up as well as datasets including inconsistent information that could not be confirmed were excluded. Local institutional review board approval was obtained.

\footnotetext{
Abbreviations: CI, confidence interval; CLO, clopidogrel; LAD, large artery disease; LAD/CE, competing etiologies (LAD and cardiac embolism); ECS, emergent extracranial carotid stenting; ESUS, embolic stroke of undetermined source; ICA, internal carotid artery; IPA, inhibition of platelet aggregation; IVT, intravenous thrombolysis; mRS, modified Rankin Scale; MCA, middle cerebral artery; MT, mechanical and/or aspiration thrombectomy; NIHSS, National Institutes of Health Stroke Scale; PH, parenchymal hemorrhage; PTA, percutaneous transluminal angioplasty; $\mathrm{SAH}$, subarachnoid hemorrhage; SD, standard deviation; sICH, symptomatic intracerebral hemorrhage; TIC, ticagrelor; TICI, Thrombolysis in Cerebral Infarction Score; TO, tandem occlusion.
}

Patients either presented primarily in the emergency department of our neurovascular center or via hospitals within or surrounding the city of Stuttgart (secondary transfer) (15). Irrespectively, endovascular therapy was based upon the initial intention to treat patients (based on a shared decision-making concept including stroke-neurologists and interventional neuroradiologists) without further triage or additional imaging procedures prior to the intervention. General anesthesia was performed on a regular basis.

Information on baseline characteristics, current medication, symptom onset, stroke severity (e.g., National Institutes of Health Stroke Scale [NIHSS], modified Rankin Scale [mRS]) or periprocedural information (e.g., Thrombolysis in Cerebral Infarction Score [TICI]) were extracted from admission notes, internal documentation, referral, or discharge papers. Imaging modality and imaging times were stored in our Picture Archiving and Communication System. Follow-up information were collected by our study nurse (via telephone calls).

TO were defined as an occlusion or high-grade stenosis (NASCET [North American Symptomatic Carotid Endarterectomy Trial] $>70 \%$ ) of the extracranial ICA with a concomitant ipsilateral occlusion of the intracranial ICA, the carotid-T or the MCA (M1 or M2 branch). We used the extracranial first approach (emergent extracranial stenting followed by intracranial MT). The following patients defined the control group: (1) embolic intracranial large vessel occlusion; (2) absence of a high-grade intra- or extracranial stenosis requiring emergent stenting; (3) treatment within $6 \mathrm{~h}$ of symptom onset; (4) MT only without additional or primary stent application.

In subgroup analyses we tried to detect possible differences in TO due to etiology or medical treatment. (1) Baseline characteristics and outcome in extracranial atherosclerosis (LAD), dissection and in patients with competing etiologies (LAD/CE; both cardiac embolism [e.g., atrial fibrillation] and LAD being possible etiologies) were compared. All patients with atrial fibrillation were summarized in LAD/CE unless a definite cause of stroke (e.g., LAD) could be determined. (2) Loading. Prior to emergent stenting, aspirin (500 mg IV) in combination with either clopidogrel (CLO; $600 \mathrm{mg}$ PO via a nasogastric tube) or ticagrelor (TIC; $180 \mathrm{mg}$ PO via a nasogastric tube) was given to inhibit platelet aggregation. The choice of the respective drug was at the discretion of the interventional neuroradiologist.

Due to a faster inhibition in platelet aggregation (IPA), TIC is currently preferred if emergent stenting is required (16). To secure an immediate IPA (until the expected effect of TIC or CLO), we implemented a bridging concept with the glycoprotein IIb/IIIa inhibitor eptifibatide (given as a single body weightadapted IV bolus) (17). Post intervention, there was strict blood pressure control (systolic blood pressure $<130 \mathrm{~mm} \mathrm{Hg}$ ) for a 
minimum of 3 days. Outcome and hemorrhagic complications in TIC and CLO were compared. After initial loading, dual IPA was continued for a minimum of 3 months (CLO [75 mg/day] or TIC [90 mg twice a day] in combination with aspirin $100 \mathrm{mg} /$ day) followed by monotherapy with aspirin lifelong. Platelet function was assessed with Multiplate ${ }^{\circledR}$ and/or VerifyNow ${ }^{\circledR}$ tests. In case of incomplete IPA, CLO was replaced by TIC. Anticoagulation (in case of atrial fibrillation) was begun depending on stroke severity (NIHSS) and the size of the infarcted tissue (18). (3) Effects of IVT in both the control group and TO on outcome and hemorrhagic complications. (4) Potential factors influencing outcome and mortality in both controls and TO.

\section{Outcome Measures}

Good functional outcome (mRS 0-2 at day 90) was the primary outcome parameter. Secondary outcome measures were: (1) development of a symptomatic intracranial hemorrhage (sICH) according to the Solitaire ${ }^{\mathrm{TM}}$ with the Intention for Thrombectomy as Primary Endovascular Treatment for Acute Ischemic Stroke (SWIFT PRIME) criteria (parenchymal hemorrhage $[\mathrm{PH}$ ] type 1 or 2 , subarachnoid hemorrhage [SAH] or intraventricular hemorrhage within $24 \mathrm{~h}$ after MT with a deterioration in the NIHSS $\geq 4$ points or leading to death) (19); (2) in-hospital mortality; (3) all-cause mortality (day 90).

\section{Statistical Analysis}

Numerical baseline characteristics were described in mean (standard deviation). Categorical baseline parameters were described in frequencies. Comparing groups, the Fisher's exact test (categorical parameters), the Kruskal-Wallis-test or the Mann-Whitney- $U$-test (numerical parameters) were used as appropriate. Analyzing more than two groups [e.g., subgroup analysis (1)] outcome in the respective group (e.g., LAD) was compared to the outcome in the remaining groups (e.g., $\mathrm{LAD} / \mathrm{CE}$ and dissection). A multivariate logistic regression model (considering possible confounders [based on literature research; $p<0.05$ in baseline characteristics]) tried to detect factors influencing outcome and mortality. A $p$-value below 0.05 was considered statistically significant. Stata/IC 13.1 for Windows (StataCorp LP, College Station, Texas, USA) was used for statistical analysis.

\section{RESULTS}

Between 2010 and 2017, $n=2450$ acute ischemic stroke patients received endovascular recanalization therapy by us. $N=1071$ (43.7\%) met the predefined inclusion criteria, $n=1379(56.3 \%)$ had to be excluded from further analysis (Figure 1). $N=222$ patients were included in TO, $n=849$ in the control group (C).

The baseline characteristics are shown in Table 1. There were significant differences (TO vs. C) in sex (male: 68.0 vs. $46.4 \%$; $p<0.001$ ), age (mean [SD]: 67.8 [12.8] vs. 73.1 [12.9]; $p<0.001$ ), atrial fibrillation ( 27.5 vs. $62.5 \%$; $p<0.001)$, smoking ( 25.3 vs. $8.6 \%$; $p<0.001)$, IVT (23.9 vs. $31.7 \% ; p=0.026)$, baseline NIHSS (mean [SD]: 14.8 [8.1] vs. 16.5 [7.6]; $p=0.001$ ), stroke etiology and target vessel (see Table 1). Time-to-recanalization was longer in TO (hours; mean [SD]: 6 (1.8) vs. $5.1(1.5) ; p<0.001)$ due

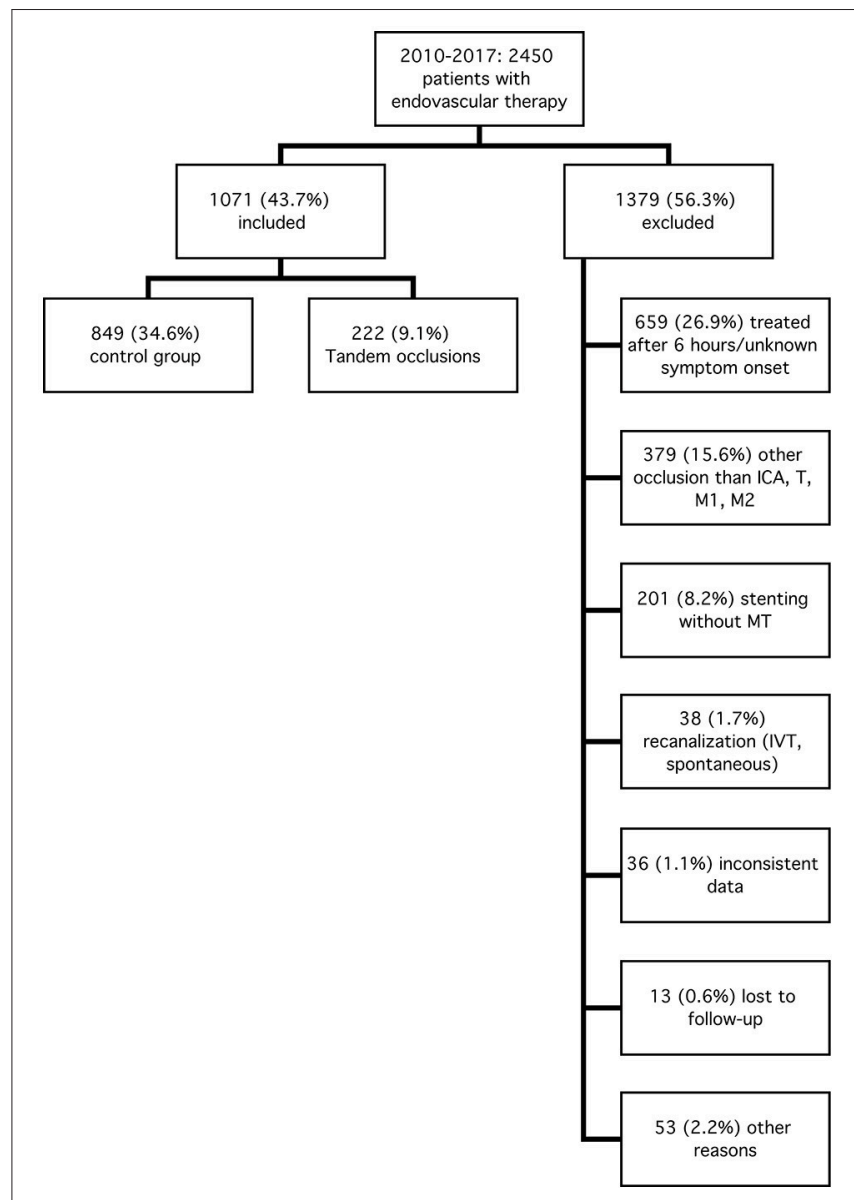

FIGURE 1 | Inclusion and exclusion criteria. ICA, internal carotid artery; T, carotid-T; M1 (M2), M1 (M2), segment of the middle cerebral artery; MT, mechanical and/or aspiration thrombectomy; IVT, intravenous thrombolysis.

to a longer duration of treatment (hours; TO: 2.3 (1.6); C: 1.5 (1.1); $p<0.001)$. There was no difference in onset-to-groin or imaging-to-groin times.

Good functional outcome was more frequent in TO $(44.6 \%)$ compared to controls (36.0\%; OR [95\% CI] 3.49 [1.59-7.67]; $p=0.002$; adjusted for differences in baseline characteristics; Table 2). We did not observe differences in in-hospital mortality (0.76 [0.45-1.30]; $p=0.324)$, all-cause mortality after 3 months (0.78 [0.47-1.29]; $p=0.324)$ and the frequency of $\mathrm{sICH}(0.70$ [0.30-1.59]; $p=0.389)$. Postinterventional SAH was more common in TO $(13.1 \%)$ than in controls $(7.1 \% ; p=0.006)$.

The difference in baseline characteristics depending on etiology (LAD $[n=149]$, LAD/CE $[n=41]$, dissection $[n=26]$ ) are shown in Table 1 (six patients were diagnosed with other etiologies than the above-mentioned and were not included in this analysis). Good functional outcome was inferior in LAD/CE (24.4\%; $0.34[0.16-0.75] ; p=0.005)$ compared to LAD $(47.7 \%$; $1.63[0.90-2.97] ; p=0.138)$ and dissection (53.8\%; 1.57 [0.693.59]; $p=0.299$; Table 3). In-hospital mortality was higher in LAD/CE $(29.3 \% ; 3.03$ [1.32-6.95]; $p=0.014)$ compared to LAD $(12.8 \% ; 0.55[0.26-1.19] ; p=0.152)$ and dissection $(7.7 \% ; 0.43$ 
TABLE 1 | Baseline characteristics, imaging findings, and time management.

\begin{tabular}{|c|c|c|c|c|c|c|c|}
\hline & \multicolumn{3}{|c|}{$\begin{array}{l}\text { Main analysis; baseline characteristics in tandem } \\
\text { occlusions vs. controls }\end{array}$} & \multicolumn{3}{|c|}{$\begin{array}{l}\text { Subgroup analysis; baseline } \\
\text { characteristics depending on etiology }\end{array}$} & \multirow[b]{2}{*}{$p$-value } \\
\hline & $\begin{array}{c}\text { TO } \\
n=222^{\star}\end{array}$ & $\begin{array}{c}\text { Controls } \\
n==849\end{array}$ & $p$-value & $\begin{array}{c}\text { Dissection } \\
n=26\end{array}$ & $\begin{array}{c}\text { LAD } \\
n=149\end{array}$ & $\begin{array}{c}\text { LAD/CE } \\
n=41\end{array}$ & \\
\hline \multicolumn{8}{|l|}{ DEMOGRAPHICS } \\
\hline Age, mean (SD), years & $67.8(12.8)$ & $73.1(12.9)$ & $<0.001$ & $48.1(10.7)$ & $69.2(10.3)$ & $75.4(10.4)$ & $<0.001$ \\
\hline Male sex, $n(\%)$ & $151(68.0)$ & $394(46.4)$ & $<0.001$ & $19(73.1)$ & $105(70.5)$ & $23(56.1)$ & 0.194 \\
\hline \multicolumn{8}{|l|}{ CARDIOVASCULAR RISK PROFILE, $n(\%)$} \\
\hline Atrial fibrillation & $61(27.5)$ & $531(62.5)$ & $<0.001$ & 0 (n.a.) & $22(14.8)$ & $39(95.1)$ & $<0.001$ \\
\hline Hypertension & $165(74.3)$ & $583(68.7)$ & 0.118 & $12(46.2)$ & $119(79.9)$ & $32(78.0)$ & 0.002 \\
\hline Diabetes mellitus II & $48(21.6)$ & $180(21.2)$ & 0.927 & $2(7.7)$ & $38(25.5)$ & $8(19.5)$ & 0.114 \\
\hline Hyperlipidemia & $51(23.0)$ & $179(21.1)$ & 0.582 & $2(7.7)$ & $37(24.8)$ & $12(29.3)$ & 0.093 \\
\hline Smoking & $52(23.4)$ & $73(8.6)$ & $<0.001$ & $7(26.9)$ & $39(26.2)$ & $6(14.6)$ & 0.307 \\
\hline Coronary artery disease & $48(21.6)$ & $231(27.2)$ & 0.103 & $2(7.7)$ & 27 (18.2) & $19(47.3)$ & $<0.001$ \\
\hline \multicolumn{8}{|l|}{ STROKE ETIOLOGY, $\boldsymbol{n}(\%)$} \\
\hline Atherothrombotic (LAD) & $149(67.1)$ & $23(2.7)$ & $<0.001$ & n.a. & n.a. & n.a. & n.a. \\
\hline Cardioembolic & 0 (n.a.) & $537(63.3)$ & $<0.001$ & n.a. & n.a. & n.a. & n.a. \\
\hline Dissection & $26(11.7)$ & $1(0.1)$ & $<0.001$ & n.a. & n.a. & n.a. & n.a. \\
\hline ESUS ‡ & 0 (n.a.) & $263(31.0)$ & $<0.001$ & n.a. & n.a. & n.a. & n.a. \\
\hline LAD/CE (LAD + cardioembolic) & $41(18.5)$ & 0 (n.a.) & $<0.001$ & n.a. & n.a. & n.a. & n.a. \\
\hline Other etiology & $6(2.7)$ & $25(2.9)$ & 1.000 & n.a. & n.a. & n.a. & n.a. \\
\hline \multicolumn{8}{|l|}{ NIHSS SCORE (BASELINE) } \\
\hline Mean (SD) & $14.8(8.1)$ & $16.5(7.6)$ & $<0.001$ & $14.7(8.2)$ & $14.6(8.5)$ & $15.9(7.0)$ & 0.495 \\
\hline \multicolumn{8}{|l|}{ IMAGING MODALITY, $\boldsymbol{n}(\%)$} \\
\hline MRI & $52(23.7)$ & $177(21.2)$ & 0.462 & $9(34.2)$ & $35(23.8)$ & $6(15.0)$ & 0.204 \\
\hline \multicolumn{8}{|c|}{ MOST PROXIMAL VESSEL OCCLUSION, $\boldsymbol{n}(\%)$} \\
\hline ICA & $14(6.3)$ & $22(2.6)$ & 0.030 & $3(11.5)$ & $6(4.0)$ & $3(7.3)$ & 0.093 \\
\hline Carotid-T & $58(26.1)$ & $195(23.0)$ & & $7(26.9)$ & $38(25.5)$ & $11(26.8)$ & \\
\hline MCA, M1 & $123(55.4)$ & $533(62.8)$ & & $9(34.6)$ & $90(60.4)$ & $22(53.7)$ & \\
\hline MCA, M2 & $27(12.2)$ & $99(11.7)$ & & $7(26.9)$ & $15(10.1)$ & $5(12.2)$ & \\
\hline IVT, $n(\%)$ & $53(23.9)$ & $269(31.7)$ & 0.026 & $7(26.9)$ & $39(26.2)$ & $5(12.2)$ & 0.147 \\
\hline \multicolumn{8}{|c|}{ TIME MANAGEMENT (HOURS), MEAN (SD) } \\
\hline Time to recanalization & $6.0(1.8)$ & $5.1(1.5)$ & $<0.001$ & $7.4(2.3)$ & $5.6(1.6)$ & $6.2(1.9)$ & $<0.001$ \\
\hline Symptom-onset to groin puncture & $3.6(1.1)$ & $3.7(1.9)$ & 0.832 & $4.0(1.3)$ & $3.5(1.0)$ & $3.8(1.1)$ & 0.135 \\
\hline Imaging to groin puncture & $2.3(0.8)$ & $2.3(0.8)$ & 0.531 & $2.3(1.1)$ & $2.2(0.8)$ & $2.4(0.8)$ & 0.343 \\
\hline Duration of treatment & $2.3(1.6)$ & $1.1(1.2)$ & $<0.001$ & $3.4(2.6)$ & $2.1(1.3)$ & $2.5(1.5)$ & $<0.001$ \\
\hline \multicolumn{8}{|l|}{ THROMBECTOMY DEVICES, $\boldsymbol{n}(\%)$} \\
\hline Penumbra ACE aspiration & $7(3.2)$ & $28(3.3)$ & 0.220 & $1(3.8)$ & $5(3.4)$ & $1(2.4)$ & 0.142 \\
\hline Solitaire stent retriever & $13(5.9)$ & $33(3.9)$ & & $2(7.7)$ & $5(3.4)$ & $6(14.6)$ & \\
\hline Phenox stent retriever & $156(70.3)$ & $626(73.7)$ & & $19(73.1)$ & $108(72.5)$ & $26(63.4)$ & \\
\hline MicroVention aspiration & $33(14.9)$ & $105(12.4)$ & & $2(7.7)$ & $25(16.8)$ & $4(9.8)$ & \\
\hline Other & $13(5.9)$ & $57(6.8)$ & & $2(7.7)$ & $6(4.1)$ & $4(9.8)$ & \\
\hline \multicolumn{8}{|l|}{ HEMORRHAGIC COMPLICATIONS, $n$ (\%) } \\
\hline $\mathrm{PH} 1$ & $7(3.2)$ & $32(3.8)$ & 0.841 & $1(3.8)$ & $5(3.4)$ & $1(2.4)$ & 1.000 \\
\hline $\mathrm{PH} 2$ & $9(4.1)$ & $33(3.9)$ & 0.848 & 0 (n.a.) & $8(5.4)$ & $1(2.4)$ & 0.655 \\
\hline $\mathrm{SAH}$ & $29(13.1)$ & $60(7.1)$ & 0.006 & $6(23.1)$ & 20 (13.4) & $2(4.9)$ & 0.091 \\
\hline Successful recanalization (TICl 2b/3), $n$ (\%) & $197(89.1)$ & $748(88.3)$ & 0.813 & $23(88.5)$ & $134(89.9)$ & $35(87.5)$ & 0.834 \\
\hline
\end{tabular}

TO, tandem occlusion; LAD, large artery disease/atherothrombotic; LAD/CE, competing etiologies (LAD plus cardiac embolism); SD, standard deviation; IVT, intravenous thrombolysis; PH, parenchymal hemorrhage; SAH, subarachnoid hemorrhage; n.a., not applicable; TICl, Thrombolysis in Cerebral Infarction; NIHSS, National Institutes of Health Stroke Scale.

${ }^{*} n$, total number of patients included in the respective group; might differ from $n$ in any category of baseline characteristics due to missing data.

‡ ESUS, embolic stroke of undetermined source. 
TABLE 2 | Outcome and safety parameters.

\begin{tabular}{|c|c|c|c|c|}
\hline & TO & Controls & OR (95\% CI) & $p$-value \\
\hline $\begin{array}{l}\text { mRS 0-2 (vs. mRS 3-6) at } 3 \\
\text { months, } n(\%)\end{array}$ & $99(44.6)$ & 306 (36.9) & $3.49(1.59-7.67)$ & 0.002 \\
\hline $\begin{array}{l}\text { In-hospital mortality (mRS } 6 \\
\text { vs. 0-5), } n(\%)\end{array}$ & $35(15.8)$ & $161(19.0)$ & $0.76(0.45-1.30)$ & 0.324 \\
\hline $\begin{array}{l}\text { All-cause mortality at } 3 \\
\text { months (mRS } 6 \text { vs. 0-5), } \\
n(\%)\end{array}$ & 48 (21.6) & $235(27.7)$ & $0.78(0.47-1.29)$ & 0.324 \\
\hline slCH (yes vs. no), $n$ (\%) & 7 (3.2) & $41(5.0)$ & $0.70(0.30-1.59)$ & 0.389 \\
\hline
\end{tabular}

TO, tandem occlusion; OR, Odds ratio; Cl, confidence interval, mRS; modified Rankin Scale; sICH, symptomatic intracranial hemorrhage.

$[0.10-1.92] ; p=0.299)$. All-cause mortality was $15.4 \%$ in patients with dissection $(0.64[0.21-1.97 ; p=0.610)$ vs. $17.4 \%$ in LAD $(0.50[0.25-0.98 ; p=0.048)$ and $39.0 \%$ in LAD/CE (3.09 [1.45$6.61 ; p=0.005)$. There was no significant difference in $\mathrm{sICH}$ (dissection: 0\%; LAD: 4.1\%; LAD/CE: 2.4\%).

In $\mathrm{TO}, n=83$ patients received a pre-medication with aspirin and CLO, $n=137$ with aspirin and TIC. Two patients had to be removed from analysis because of inconsistent information. There was no difference in good functional outcome (adjusted for differences in respective baseline characteristics; CLO vs. TIC: 44.6 vs. $45.3 \% ; 1.04$ [0.51-2.09]; $p=0.920)$, in-hospital mortality (10.8 vs. $17.5 \%$; $0.46[0.17-1.25] ; p=0.129)$ and allcause mortality after 90 days (16.9 vs. $23.4 \%$; 0.75 [0.27-2.13]; $p=0.594$; Table 3). sICH were more frequent in TIC $(n=$ $7 ; 5.1 \%)$ compared to CLO $(n=0 ; p=0.048$; due to the total $n=7$, a multivariate logistic regression for $\mathrm{sICH}$ was not calculated) as were SAH (CLO: 4,8\%; TIC: $18.2 \%$; $p=0.004)$. PH1 (CLO: $0 \%$; TIC: $4.4 \% ; p=0.086$ ) and PH2 (CLO: $1.2 \%$; TIC: $5.8 \% ; p=0.158)$ were more frequent in CLO without reaching statistical significance. TICI $2 \mathrm{~b} / 3$ was observed in $95.2 \%$ (CLO) and $86.0 \%$ (TIC) of patients respectively $(p=0.040)$.

In univariate analysis in controls, good functional outcome was observed in $40.9 \%$ of patients treated with IVT prior to endovascular therapy vs. $33.8 \%$ in non-IVT patients (1.36 [1.011.83]; $p=0.046$ ). All-cause mortality after IVT (in controls) was 18.6 vs. $31.9 \%(0.49$ [0.34-0.70]; $p<0.001)$. In TO, there was no such difference (IVT vs. non-IVT; mRS 0-2: 43.4 vs. $45.0 \%$; 0.94 [0.50-1.75]; $p=0.875$; mRS 6 at 3 months: 20.8 vs. $21.9 \% ; 0.93$ [0.44-2.00]; $p=1.000)$. IVT had no influence on the development of sICH in both controls (IVT vs. non-IVT: 5.7 vs. $4.6 \%$; $1.25[0.65-2.41] ; p=0.495)$ and TO (1.9 vs. $3.6 \%$; 0.53 [0.06-4.53]; $p=1.000$ ). In our cohort, there was no clear association between IVT and TICI $2 \mathrm{~b} / 3$ in TO (IVT vs. non-IVT: 88.7 vs. $89.3 \% ; 0.94[0.35-2.51] ; p=1.000)$ or controls (89.9 vs. $87.6 \% ; 1.26$ [0.79-2.01]; $p=0.359)$. In multivariate analysis, IVT was (in controls only) associated with a reduction in all-cause mortality (0.46 [0.30-0.69]; $p<0.001$, Table 4).

To detect factors influencing outcome, separate multivariate logistic regression models were calculated for $\mathrm{TO}$ and controls (Table 4). Age (mRS 0-2: TO: 0.95 [0.92-0.99], $p=0.007$; C: 0.94 [0.93-0.96], $p<0.001$; mRS 6: TO: 1.10 [1.05-1.16], $p<0.001$; C: 1.09 [1.06-1.11], $p<0.001)$ and NIHSS (mRS

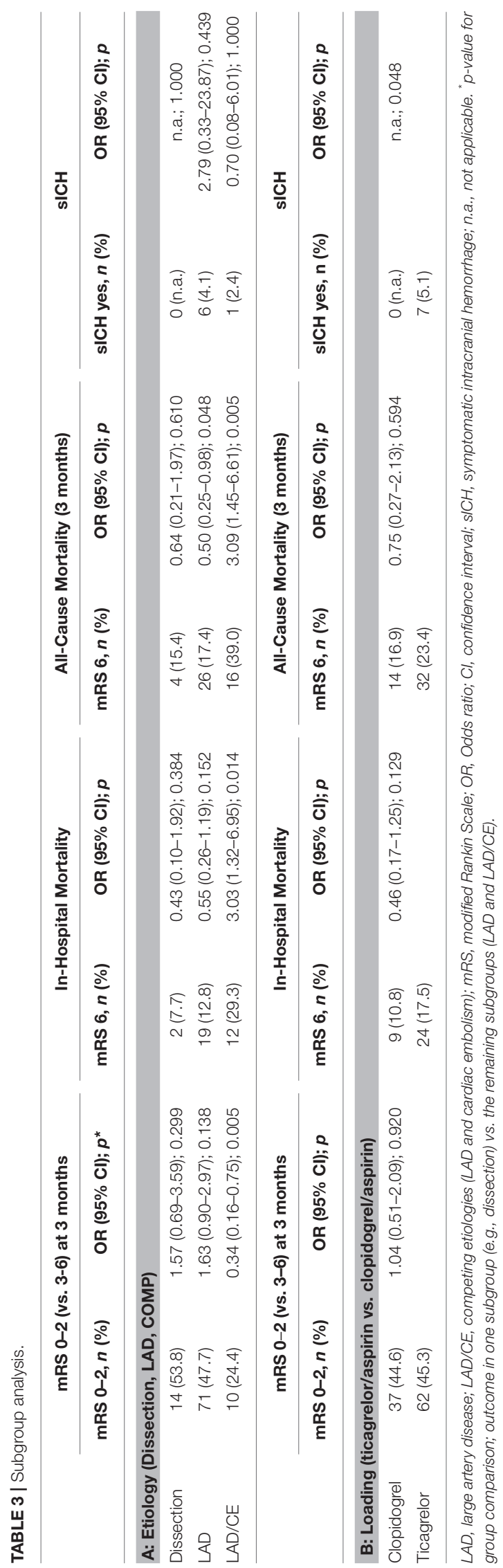


TABLE 4 | Multivariate logistic regression (good functional outcome, all-cause mortality).

\begin{tabular}{|c|c|c|c|c|}
\hline & \multicolumn{2}{|c|}{$\begin{array}{c}\text { mRS 0-2 (vs. 3-6) at } \\
3 \text { months }\end{array}$} & \multicolumn{2}{|c|}{$\begin{array}{c}\text { mRS } 6 \text { (vs. 0-5) at } 3 \\
\text { months }\end{array}$} \\
\hline & OR (95\% Cl) & $p$-value & OR (95\% Cl) & $p$-value \\
\hline \multicolumn{5}{|l|}{ A: Control group } \\
\hline Male (vs. female) & n.s. & n.s. & n.s. & n.s. \\
\hline Atrial fibrillation & n.s. & n.s. & $0.50(0.34-0.76)$ & 0.001 \\
\hline Diabetes mellitus type II & n.s. & n.s. & n.s. & n.s. \\
\hline Hyperlipidemia & n.s. & n.s. & n.s. & n.s. \\
\hline Smoker & n.s. & n.s. & n.s. & n.s. \\
\hline Hypertension & n.s. & n.s. & $0.53(0.36-0.80)$ & 0.002 \\
\hline Coronary artery disease & n.s. & n.s. & n.s. & n.s. \\
\hline $\mathrm{TICl} 2 \mathrm{~b} / 3$ & $2.30(1.09-4.90)$ & 0.030 & $0.43(0.25-0.74)$ & 0.002 \\
\hline Vessel occlusion: M2 & n.s. & n.s. & n.s. & n.s. \\
\hline IVT & n.s. & n.s. & $0.43(0.28-0.66)$ & $<0.001$ \\
\hline Age & $0.94(0.93-0.96)$ & $<0.001$ & $1.09(1.06-1.11)$ & $<0.001$ \\
\hline NIHSS & $0.90(0.87-0.92)$ & $<0.001$ & $1.10(1.07-1.13)$ & $<0.001$ \\
\hline Duration of treatment & $0.53(0.42-0.66)$ & $<0.001$ & $1.20(1.00-1.43)$ & 0.050 \\
\hline $\begin{array}{l}\text { Symptom-onset to } \\
\text { groin puncture }\end{array}$ & $0.72(0.60-0.85)$ & $<0.001$ & $1.50(1.24-1.81)$ & $<0.001$ \\
\hline Time to recanalization & $0.72(0.60-0.85)$ & $<0.001$ & $1.33(1.17-1.52)$ & $<0.001$ \\
\hline \multicolumn{5}{|l|}{ B: Tandem occlusions } \\
\hline Male (vs. female) & n.s. & n.s. & n.s. & n.s. \\
\hline Atrial fibrillation & $0.34(0.14-0.81)$ & 0.015 & n.s. & n.s. \\
\hline Diabetes mellitus type II & $0.31(0.13-0.73)$ & 0.007 & n.s. & n.s. \\
\hline Hyperlipidemia & $2.99(1.17-7.60)$ & 0.022 & $0.10(0.03-0.38)$ & 0.001 \\
\hline Smoker & n.s. & n.s. & n.s. & n.s. \\
\hline Hypertension & n.s. & n.s. & n.s. & n.s. \\
\hline Coronary artery disease & n.s. & n.s. & $2.43(1.00-5.90)$ & 0.049 \\
\hline $\mathrm{TICl} 2 \mathrm{~b} / 3$ & * & * & n.s. & n.s. \\
\hline Vessel occlusion: M2 & $3.54(1.07-11.67)$ & 0.038 & n.s. & n.s. \\
\hline IVT & n.s. & n.s. & n.s. & n.s. \\
\hline Age & 0.95 (0.92-0.99) & 0.007 & $1.10(1.05-1.16)$ & $<0.001$ \\
\hline $\mathrm{NIHSS}$ & $0.90(0.86-0.95)$ & $<0.001$ & $1.06(1.01-1.11)$ & 0.31 \\
\hline Duration of treatment & $0.54(0.35-0.82)$ & 0.004 & $1.58(1.23-2.03)$ & $<0.001$ \\
\hline $\begin{array}{l}\text { Symptom-onset to } \\
\text { groin puncture }\end{array}$ & n.s. & n.s. & n.s. & n.s. \\
\hline Time to recanalization & n.s. & n.s. & 1.57 (1.26-1.95) & $<0.001$ \\
\hline
\end{tabular}

mRS, modified Rankin Scale; OR, Odds ratio; Cl, confidence interval; NIHSS, National Institutes of Health Stroke Scale; TICI, Thrombolysis In Cerebral Infarction; n.s., not significant; M2, M2-Segment of the middle cerebral artery; IVT; intravenous thrombolysis. * all patients with TICI 0-2a presented with an mRS 3-6 at follow-up; TICI 0-2 is a perfect predictor for a negative outcome in this subgroup (TO).

0-2; TO: 0.90 [0.86-0.95], $p<0.001$; C: 0.90 [0.87-0.92], $p<$ 0.001 ; mRS 6: TO: 1.06 [1.01-1.11], $p=0.031$; C: 1.10 [1.071.13 ], $p<0.001$ ) showed significant associations. In TO, there was a negative association with atrial fibrillation $(0.34[0.14-$ $0.81], p=0.015)$ and diabetes mellitus type II (0.31 [0.13-0.73], $p=0.007)$ while hyperlipidemia (2.99 [1.17-7.60], $p=0.022)$ and target vessel M2 (3.54 [1.07-11.67], $p=0.038$ ) were shown to be associated with a good outcome (2.99 [1.17-7.60], $p=0.022)$. In controls, TICI $2 \mathrm{~b} / 3$ was significantly correlated with good functional outcome (2.30 [1.09-4.90], $p=0.030)$ and all-cause mortality $(0.43[0.25-0.74, \mathrm{p}=0.002)$. In TO, TICI $2 \mathrm{~b} / 3$ could not be considered in multivariate analysis (for good functional outcome) as all patients with TICI $0-2$ a had mRS 3-6 in 3 month follow-up. In this cohort, TICI 0 -2a was a perfect negative predictor. Time dependency in controls was evident for both symptom-onset to groin time (0.72 [0.60-0.85], $p<0.001)$ and duration of treatment $(0.53[0.42-0.66], p<0.001)$. In TO, only duration of treatment $(0.54$ [0.35-0.82], $p=0.004)$ but not symptom-to-groin time or time to recanalization correlated significantly with outcome. Factors associated with mortality are shown in Table 4.

\section{DISCUSSION}

The main finding of our study was that outcome after endovascular therapy in TO using the extracranial first approach was shown to be superior compared to controls (patients with an acute ischemic stroke due to intracranial large vessel occlusion without concomitant high-grade extracranial stenosis of the ipsilateral ICA). Mortality rates did not differ. Despite the need of dual IPA after emergent stenting in TO, we did not observe an increase in sICH when compared to controls.

Evidence on endovascular treatment strategies in TO is mixed and inconsistent $(7,8,10)$. Some authors suggest intracranial MT to be done before ECS (intracranial first) in order to minimize the time of critical hypoperfusion $(8,14)$. Currently, this seems to be the most widespread approach (9). However, ECS requires dual IPA which-especially in acute ischemic stroke-might increase the rate of hemorrhagic complications. Therefore, it is argued that a PTA should be performed in the acute setting while ECS in general (or vascular surgery) has to follow later during the course of the disease (9). Besides in an increase in (asymptomatic) $\mathrm{SAH}$ we did not observe additional hemorrhagic complications in our cohort. Most importantly, dual IPA did not increase the frequency of sICH. A third proposed treatment option is extracranial first $(7,9,10)$. Immediately recanalizing the proximal ICA might improve or uphold crucial collateralization (21, 22). Asymptomatic ICA-stenosis can be compensated through a change in cerebral blood flow via existing or established collaterals (e.g., the Circle of Willis). A consistent reduction in cerebral perfusion (due to ICA-stenosis) might induce additional collaterals. Atherothrombotic stroke therefore is said to have greater collateral recruitment compared to stroke due to other etiologies (23). Together with possible effects of ischemic preconditioning of the brain, this could have a positive effect on outcome in TO (24). Yet, in progressive ICA-stenosis or acute occlusion, those compensation mechanisms might fail (25-29). In our cohort, time to recanalization was significantly longer in TO. Unlike the control population, where an association between symptom-onset to groin puncture time and good functional outcome was shown, symptom-onset to groin puncture time (and time to recanalization) did not significantly influence outcome in TO. This might also emphasize the importance of pre-existing collaterals. So far, superiority of any endovascular approach in TO could not be demonstrated (10). An average symptom-onset 
to groin puncture time of $3.6 \mathrm{~h}$ ( $\mathrm{TO} ; 3.7 \mathrm{~h}$ in controls) is attributed to the high number of secondary referrals (15).

The use of dual IPA in TO did not lead to an increase in symptomatic intracranial hemorrhages. The frequency of asymptomatic SAH (as seen on follow-up imaging) was significantly higher in TO. CLO is widely used in dual IPA after coronary, extra- or intracranial stenting. After loading, it takes 6 to $12 \mathrm{~h}$ until a sufficient inhibition in platelet activity is established (16). IPA in TIC is established after about $3 \mathrm{~h}$ (16). A faster IPA might reduce early complications (e.g., stent thrombosis) and therefore add an extra benefit. However, especially in dual IPA, TIC might introduce additional hemorrhagic complications $(30,31)$. From 2016/2017 onwards, we loaded patients with TIC and aspirin on a regular basis. Comparing CLO and TIC, we did not observe differences in outcome. Similar to previous data, there was a significant increase in major and minor hemorrhagic complications ( $\mathrm{sICH}, \mathrm{SAH})$ after pre-medication with TIC $(30,31)$.

In our dataset, outcome after cervical ICA-dissection and LAD was superior compared to patients with LAD/CE (both LAD and cardioembolic etiology possible). Mortality in dissection was significantly lower. Favorable outcome in dissections-patients are younger without a typical cardiovascular risk profile-is wellknown (32). In contrast, patients with cardioembolic stroke due to atrial fibrillation are older, stroke is more severe and has a higher risk of recurrence (33). Outcome in cardioembolic stroke, even after MT in a reasonable time window-is inferior to stroke caused by other etiologies $(34,35)$. The combination of LAD (or vascular disease in general) and atrial fibrillation has a further negative effect on functional outcome $(36,37)$. Other potential factors such as contraindications (e.g., major stroke and necessity of anticoagulation) or triple therapy are open for discussion.

Age, NIHSS and successful reperfusion have been identified as prognostic parameters in TO before (20). In our cohort, age and NIHSS showed a similar correlation in both TO and controls. TICI $2 \mathrm{~b} / 3$ was associated with good functional outcome and a reduction in all-cause mortality in controls. In TO, TICI 0-2a was a perfect predictor for a poor outcome as all patients with TICI 02 a got mRS 3-6 after 3 months. IVT is said to be associated with successful reperfusion in patients with TO $(38,39)$. In univariate analysis, we observed better functional outcome and reduced allcause mortality in controls treated with IVT prior to MT (but not

\section{REFERENCES}

1. Berkhemer OA, Fransen PS, Beumer D, van den Berg LA, Lingsma HF, Yoo AJ, et al. A randomized trial of intraarterial treatment for acute ischemic stroke. N Engl J Med. (2015) 372:11-20. doi: 10.1056/NEJMoa14 11587

2. Goyal M, Demchuk AM, Menon BK, Eesa M, Rempel JL, Thornton $\mathrm{J}$, et al. Randomized assessment of rapid endovascular treatment of ischemic stroke. N Engl J Med. (2015) 372:1019-30. doi: 10.1056/NEJMoa14 14905

3. Saver JL, Goyal M, Bonafe A, Diener HC, Levy EI, Pereira VM, et al. StentRetriever thrombectomy after Intravenous t-PA vs. t-PA alone in stroke. New Engl J Med. (2015) 372:2285-95. doi: 10.1056/NEJMoa1415061 in TO). In TO, IVT was safe and did not lead to an increase in sICH. As shown before, we observed a beneficial effect of high cholesterol levels (in TO) on short-term outcome (40).

The main limitation of the study is its retrospective design. There is no information on patients where MT was not considered which might introduce selection bias. A certain inconsistency in decision-making has to be expected. Small sample sizes in subgroup analyses might lead to a power problem resulting in a potential underestimation of therapeutic or predictive effects. As there was no common study protocol, there is no information on potential contraindications or off-label decisions (e.g., IVT, dual IPA, individual healing attempts).

\section{CONCLUSION}

Endovascular therapy in acute ischemic stroke due to TO using the extracranial first approach allows for a good functional outcome. In our cohort, dual IPA after emergent stenting in acute ischemic stroke patients was safe and did not lead to an overall increase in the frequency of sICH. Sufficiently powered randomized-controlled trials are needed for direct comparison of the different therapeutic strategies. In subgroup analysis focusing on dual IPA, TIC, and CLO did not differ in terms of outcome and mortality. However, TIC lead to a significant increase in sICH and SAH when compared to CLO. IVT-admission did not cause additional hemorrhagic complications.

\section{DATA AVAILABILITY STATEMENT}

All relevant data is contained within the manuscript.

\section{AUTHOR CONTRIBUTIONS}

PB: study concept and drafting of the manuscript. All authors contributed to the acquisition, analysis and interpreting of data, and to the critical revision and final approval of the manuscript.

\section{ACKNOWLEDGMENTS}

C. Knispel as the stroke and study nurse essentially contributed to the collection of the data. H. Niggemann did the statistical analysis. L. Bloom has done the native speaker language revision of this manuscript.

4. Campbell BC, Mitchell PJ, Kleinig TJ, Dewey HM, Churilov L, Yassi N, et al. Endovascular therapy for ischemic stroke with perfusion-imaging selection. N Engl J Med. (2015) 372:1009-18. doi: 10.1056/NEJMoal4 14792

5. Jovin TG, Chamorro A, Cobo E, de Miquel MA, Molina CA, Rovira A, et al. Thrombectomy within 8 hours after symptom onset in ischemic stroke. N Engl J Med. (2015) 372:2296-306. doi: 10.1056/NEJMoa15 03780

6. Wahlgren N, Moreira T, Michel P, Steiner T, Jansen O, Cognard C, et al. Mechanical thrombectomy in acute ischemic stroke: consensus statement by ESO-Karolinska Stroke Update 2014/2015, supported by ESO, ESMINT, ESNR and EAN. Int J Stroke (2016) 11:134-47. doi: $10.1177 / 1747493015609778$ 
7. Assis Z, Menon BK, Goyal M, Demchuk AM, Shankar J, Rempel $\mathrm{JL}$, et al. Acute ischemic stroke with tandem lesions: technical endovascular management and clinical outcomes from the ESCAPE trial. J Neurointerv Surg. (2018) 10:429-33. doi: 10.1136/neurintsurg-2017-0 13316

8. Sivan-Hoffmann R, Gory B, Armoiry X, Goyal M, Riva R, Labeyrie $\mathrm{PE}$, et al. Stent-retriever thrombectomy for acute anterior ischemic stroke with tandem occlusion: a systematic review and metaanalysis. Eur Radiol. (2017) 27:247-54. doi: 10.1007/s00330-016-4 338-y

9. Rangel-Castilla L, Rajah GB, Shakir HJ, Shallwani H, Gandhi S, Davies $\mathrm{JM}$, et al. Management of acute ischemic stroke due to tandem occlusion: should endovascular recanalization of the extracranial or intracranial occlusive lesion be done first? Neurosurg Focus (2017) 42:E16. doi: 10.3171/2017.1.FOCUS16500

10. Wilson MP, Murad MH, Krings T, Pereira VM, O'Kelly C, Rempel J, et al. Management of tandem occlusions in acute ischemic stroke - intracranial versus extracranial first and extracranial stenting versus angioplasty alone: a systematic review and meta-analysis. J Neurointerv Surg. (2018) 10:721-28. doi: 10.1136/neurintsurg-2017-013707

11. Mishra A, Stockley H, Goddard T, Sonwalker H, Wuppalapati S, Patankar T. Emergent extracranial internal carotid artery stenting and mechanical thrombectomy in acute ischaemic stroke. Interv Neuroradiol. (2015) 21:20514. doi: $10.1177 / 1591019915583213$

12. Cohen JE, Leker RR, Eichel R, Gomori M, Itshayek E. Emergency endovascular revascularization of tandem occlusions: internal carotid artery dissection and intracranial large artery embolism. J Clin Neurosci. (2016) 28:157-61. doi: 10.1016/j.jocn.2015.12.003

13. Akpinar S, Gelener P. Endovascular treatment of acute tandem occlusion strokes and stenting first experience. J Clin Neurosci. (2018) 47:328-31. doi: 10.1016/j.jocn.2017.09.010

14. Mpotsaris A, Kabbasch C, Borggrefe J, Gontu V, Soderman M. Stenting of the cervical internal carotid artery in acute stroke management: the karolinska experience. Interv Neuroradiol. (2017) 23:159-65. doi: $10.1177 / 1591019916681983$

15. Bücke P, Pérez MA, Schmid E, Nolte $C H$, Bäzner $H$, Henkes $H$. Endovascular thrombectomy in acute ischemic stroke: outcome in referred versus directly admitted patients. Clin Neuroradiol. (2018) 28:235-44. doi: $10.1007 / \mathrm{s} 00062-017-0558-\mathrm{z}$

16. Bergmeijer TO, Godschalk TC, Janssen PWA, Berge KVD, Breet NJ, Kelder JC, et al. How long does it take for clopidogrel and ticagrelor to inhibit platelets in patients undergoing primary percutaneous coronary intervention? a detailed pharmacodynamic analysis: time course of platelet reactivity in STEMI (TOPS). Semin Thromb Hemost. (2017) 43:439-46. doi: 10.1055/s-0037-1599156

17. Shimada YJ, Bansilal S, Wiviott SD, Becker RC, Harrington RA, Himmelmann A, et al. Impact of glycoprotein IIb/IIIa inhibitors on the efficacy and safety of ticagrelor compared with clopidogrel in patients with acute coronary syndromes: analysis from the Platelet Inhibition and Patient Outcomes (PLATO) Trial. Am Heart J. (2016) 177:1-8. doi: 10.1016/j.ahj.2016.0 3.015

18. Heidbuchel H, Verhamme P, Alings M, Antz M, Diener HC, Hacke W, et al. Updated European Heart Rhythm Association Practical Guide on the use of non-vitamin Kantagonist anticoagulants in patients with non-valvular atrial fibrillation. Europace (2015) 17:1467-507. doi: 10.1093/europace/e uv309

19. Saver JL, Goyal M, Bonafe A, Diener HC, Levy EI, Pereira VM, et al. Solitaire ${ }^{\mathrm{TM}}$ with the Intention for Thrombectomy as Primary Endovascular Treatment for Acute Ischemic Stroke (SWIFT PRIME) trial: protocol for a randomized, controlled, multicenter study comparing the Solitaire revascularization device with IV tPA with IV tPA alone in acute ischemic stroke. Int J Stroke (2015) 10:439-48. doi: 10.1111/ijs. 12459

20. Grigoryan M, Haussen DC, Hassan AE, Lima A, Grossberg J, Rebello LC, et al. Endovascular treatment of acute ischemic stroke due to tandem occlusions: large multicenter series and systematic review. Cerebrovasc Dis. (2016) 41:306-12. doi: 10.1159/0004 44069
21. Sallustio F, Motta C, Koch G, Pizzuto S, Campbell BC, Diomedi $\mathrm{M}$, et al. Endovascular stroke treatment of acute tandem occlusion: a single-center experience. J Vasc Interv Radiol. (2017) 28:543-49. doi: 10.1016/j.jvir.2017.01.007

22. Maus V, Behme D, Borggrefe J, Kabbasch C, Seker F, Hüseyin C, et al. Carotid artery stenosis contralateral to acute tandem occlusion: an independent predictor of poor clinical outcome after mechanical thrombectomy with concomitant carotid artery stenting. Cerebrovasc Dis. (2018) 45:10-17. doi: 10.1159/0004 84719

23. Rebello LC, Bouslama M, Haussen DC, Grossberg JA, Dehkharghani S, Anderson A, et al. Stroke etiology and collaterals: atheroembolic strokes have greater collateral recruitment than cardioembolic strokes. Eur J Neurol. (2017) 24:762-67 doi: 10.1111/ene.13287

24. Moncayo J, de Freitas GR, Bogousslavsky J, Altieri M, van Melle G. Do transient ischemic attacks have a neuroprotective effect? Neurology (2000) 54:2089-94. doi: 10.5114/aoms.2016. 63744

25. Fürst $\mathrm{H}$, Hartl WH, Janssen I. Patterns of cerebrovascular reactivity in patients with unilateral asymptomatic carotid artery stenosis. Stroke (1994) 25:1193200.

26. Manojlovic V, Popovic V, Nikoloc D, Milosevic D, Pasternak J, Budakov N. Completeness of circle of willis in asymptomatic and symptomatic extracranial carotid disease. Med Pregl. (2016) 69:351-55. doi: 10.2298/MPNS1612351M

27. Guo ZN, Sun X, Liu J, Sun H, Zhao Y, Ma H, et al. The impact of variational primary collaterals on cerebral autoregulation. Front Physiol. (2018) 9:759. doi: 10.3389/fphys.2018.00759

28. Shakur SF, Amin-Hanjani S, Bednarski C, Du X, Aletich VA, Charbel FT, et al. Intracranial blood flow changes after extracranial carotid artery stenting. Neurosurgery (2015) 76:330-6. doi: 10.1227/NEU.00000000000 00618

29. Shakur SF, Hrbac T, Alaraj A, Du X, Aletich VA, Charbel FT, et al. Effects of extracranial carotid stenosis on intracranial blood flow. Stroke (2014) 45:3427-9. doi: 10.1161/STROKEAHA.114.0 06622

30. Verlinden NJ, Coons JC, Iasella CJ, Kane-Gill SL. Triple antithrombotic therapyWith aspirin, P2Y12 inhibitor, and warfarin after percutaneous coronary intervention: an evaluation of prasugrel or ticagrelor versus clopidogrel. $J$ Cardiovasc Pharmacol Ther. (2017) 22:546-51. doi: 10.1177/10742484176 98042

31. Andreou I, Briasoulis A, Pappas C, Ikonomidis I, Alexopoulos D. Ticagrelor versus clopidogrel as part of dual or triple antithrombotic therapy: a systematic review and Meta-analysis. Cardiovasc Drugs Ther. (2018) doi: 10.1007/s10557-018-6795-9. [Epub ahead of print].

32. Béjot Y, Daubail B, Debette S, Durier J, Giroud M. Incidence and outcome of cerebrovascular events related to cervical artery dissection: the dijon stroke registry. Int J Stroke (2014) 9:879-82. doi: 10.1111/ijs. 12154

33. Arauz A, Ruiz-Navarro F, Barboza MA, Ruiz A, Colin J, Reyes M, et al. Outcome, recurrence and mortality after non-valvular atrial fibrillation stroke: long-term follow-up study. J Vasc Interv Neurol. (2017) 9:5-11.

34. McGrath ER, Kapral MK, Fang J, Eikelboom JW, Conghaile AÓ, Canavan $\mathrm{M}$, et al. Association of atrial fibrillation with mortality and disability after ischemic stroke. Neurology (2013) 81:825-32. doi: 10.1212/WNL.0b013e3182a $2 \mathrm{cc} 15$

35. Giray S, Ozdemir O, Baş DF, Inanç Y, Arlier Z, Kocaturk O. Does stroke etiology play a role in predicting outcome of acute stroke patients who underwent endovascular treatment with stent retrievers? J Neurol Sci. (2017) 372:104-09. doi: 10.1016/j.jns.2016. 11.006

36. Aguilar E, García-Díaz AM, Sánchez Muñoz-Torrero JF, Alvarez LR, Piedecausa M, Arnedo G, et al. Clinical outcome of stable outpatients with coronary, cerebrovascular or peripheral artery disease, and atrial fibrillation. Thromb Res. (2012) 130:390-5. doi: 10.1016/j.thromres.2012. 05.016 
37. Olesen JB, Gislason GH, Torp-Pedersen C, Lip GY. Atrial fibrillation and vascular disease-a bad combination. Clin Cardiol. (2012) 35:15-20. doi: $10.1002 /$ clc. 20955

38. Cobb MI, Bruce DJ, Graffagnino C, Hauck EF. Symbiotic relationship of IV-tPA and mechanical thrombectomy in a case of acute tandem ICAMCA occlusion. J Clin Neurosci. (2017) 38:68-71. doi: 10.1016/j.jocn.2016. 12.025

39. Gory B, Haussen DC, Piotin M, Steglich-Arnholm H, Holtmannspötter $\mathrm{M}$, Labreuche J, et al. Impact of intravenous thrombolysis and emergent carotid stenting on reperfusion and clinical outcomes in patients with acute stroke with tandem lesion treated with thrombectomy: a collaborative pooled analysis. Eur J Neurol. (2018) 25:1115-20. doi: 10.1111/ene. 13633

40. Vauthey C, de Freitas GR, van Melle G, Devuyst G, Bogousslavsky J. Better outcome after stroke with higher serum cholesterol levels. Neurology (2000) 54(10):1944-9. doi: 10.1212/WNL.54.10.1944
Conflict of Interest Statement: The authors do not refer to specific medical devices since they are beyond the scope of this work. $\mathrm{HH}$ is co-founder and shareholder of phenox GmbH. MA has a proctoring and consulting agreement with phenox $\mathrm{GmbH}$.

The remaining authors declare that the research was conducted in the absence of any commercial or financial relationships that could be construed as a potential conflict of interest

Copyright $\odot 2018$ Bücke, Aguilar Pérez, AlMatter, Hellstern, Bäzner and Henkes. This is an open-access article distributed under the terms of the Creative Commons Attribution License (CC BY). The use, distribution or reproduction in other forums is permitted, provided the original author(s) and the copyright owner(s) are credited and that the original publication in this journal is cited, in accordance with accepted academic practice. No use, distribution or reproduction is permitted which does not comply with these terms. 